\title{
Vía de señalización Notch y nuevas estrategias para el tratamiento de cáncer
}

\author{
Leticia Santos, MC, D ra en C, (1) María Fabiola León-Galván, MC,(1)
}

Erika Nahomy Marino-Marmolejo, Q BP. ${ }^{(1)}$

\section{Santos L, León-Galván MF, Marino-Marmolejo EN. Vía de señalización Notch y nuevas estrategias para el tratamiento de cáncer. Salud Publica Mex 2006;48:155-165.}

\section{Resumen}

La vía de señalización $N$ otch desempeña un papel fundamental en las diferentes etapas del desarrollo celular como la proliferación, crecimiento, diferenciación y apoptosis. Estudios recientes han demostrado que, dependiendo del nivel de expresión y del contexto celular, los receptores de membrana $\mathrm{N}$ otch contribuyen en la resistencia a apoptosis en células tumorales. Estos descubrimientos sugieren que componentes de la vía de señalización $N$ otch son un blanco potencial para el desarrollo de terapias más efectivas contra el cáncer. Esta revisión describe la función de la vía N otch y nuevas estrategias utilizadas en la modulación de su señal.

Palabras clave: N otch, cáncer, agentes terapéuticos; México

\section{Santos L, León-Galván MF, Marino-Marmolejo EN. Notch signaling pathway and new strategies in cancer treatment.}

Salud Publica Mex 2006;48:155-165.

\begin{abstract}
A bstract
The N otch signaling pathway plays a crucial role at different stages of cell development, such as proliferation, growth, differentiation, and apo ptosis. Recent studies demonstrate that depending on the expression level and cellular context, the $N$ otch receptors play a role in apoptosis resistance in malignant cells. These findings suggest that N otch signaling components may be a potential target in the development of new cancer therapies. This review describes the function of the $\mathrm{N}$ otch pathway and new strategies in the modulation of its signal.
\end{abstract}

Key words: N otch; cancer; ther apeutic agents; Mexico
$\mathrm{L}$ a vía de señalización Notch está involucrada en el control de diversos eventos durante el desarrollo de las células eucarióticas como son la proliferación, el crecimiento, la migración, la diferenciación y la muerte celular programada (apoptosis).

Thomas Hunt Morgan describió al sistema Notch, por primera vez, en 1917, como responsable de la neu- rogénesis y la especificación del ectodermo en la mosca de la fruta (Drosophila melanogaster). ${ }^{1}$ En 1914 Dexter y colaboradores descubrieron la primera mutación del gen Notch. En 1919 Mohr y colaboradores lo caracterizaron al detectar una deficiencia funcional de la proteína Notch, que provoca la aparición de surcos (notches) en los bordes de las alas de D. melanogaster. En 1940

(1) División de Biología Molecular, Instituto Potosino de Investigación Científica y Tecnológica,A.C. San Luis Potosí, S.L.P., México.

Fecha de recibido: 28 de octubre de 2004 - Fecha de aprobado: 28 de noviembre del 2005 Solicitud de sobretiros:D ra. Leticia Santos, Camino a la Presa San José 2055, Col. Lomas 4a. Sección, 78216, San Luis Potosí, S.L.P., México. Correo electrónico: Isantos@ ipicyt.edu.mx 
Poulson demostró que la pérdida del gen es letal en embriones. Posteriormente, en 1970, Wright encontró que las mutaciones del gen Notch-1 inducen la formación de una estirpe neurogénica en células que estaban destinadas a ser epidérmicas. ${ }^{2,3}$ A mediados de los años ochenta, los grupos de Artavanis-Tsakonas y Young clonaron y expresaron independientemente el gen que consiste en un receptor con un solo dominio transmembranal. ${ }^{4,5}$ A la fecha, se han identificado varios genes del receptor Notch en diversas especies, incluyendo la humana y en ratón, en las que se conocen cuatro genes que codifican a sus correspondientes proteínas Notch1 al -4 .

\section{Vía de señalización N otch}

Los genes Notch codifican receptores transmembranales de aproximadamente 300 kilodaltones $(\mathrm{kDa})$, cuya estructura está altamente conservada. Los productos de cada gen se expresan como un solo polipéptido precursor (pre-Notch, figura 1) que es procesado proteolíticamente por una convertasa en el aparato de Golgi, dando lugar a un precursor heterodimérico. Este último se ancla posteriormente en la membrana y consiste en una subunidad extracelular (extracellular subunit, EC) y una subunidad transmembranal (transmembrane subunit, TM) que está unida a la región

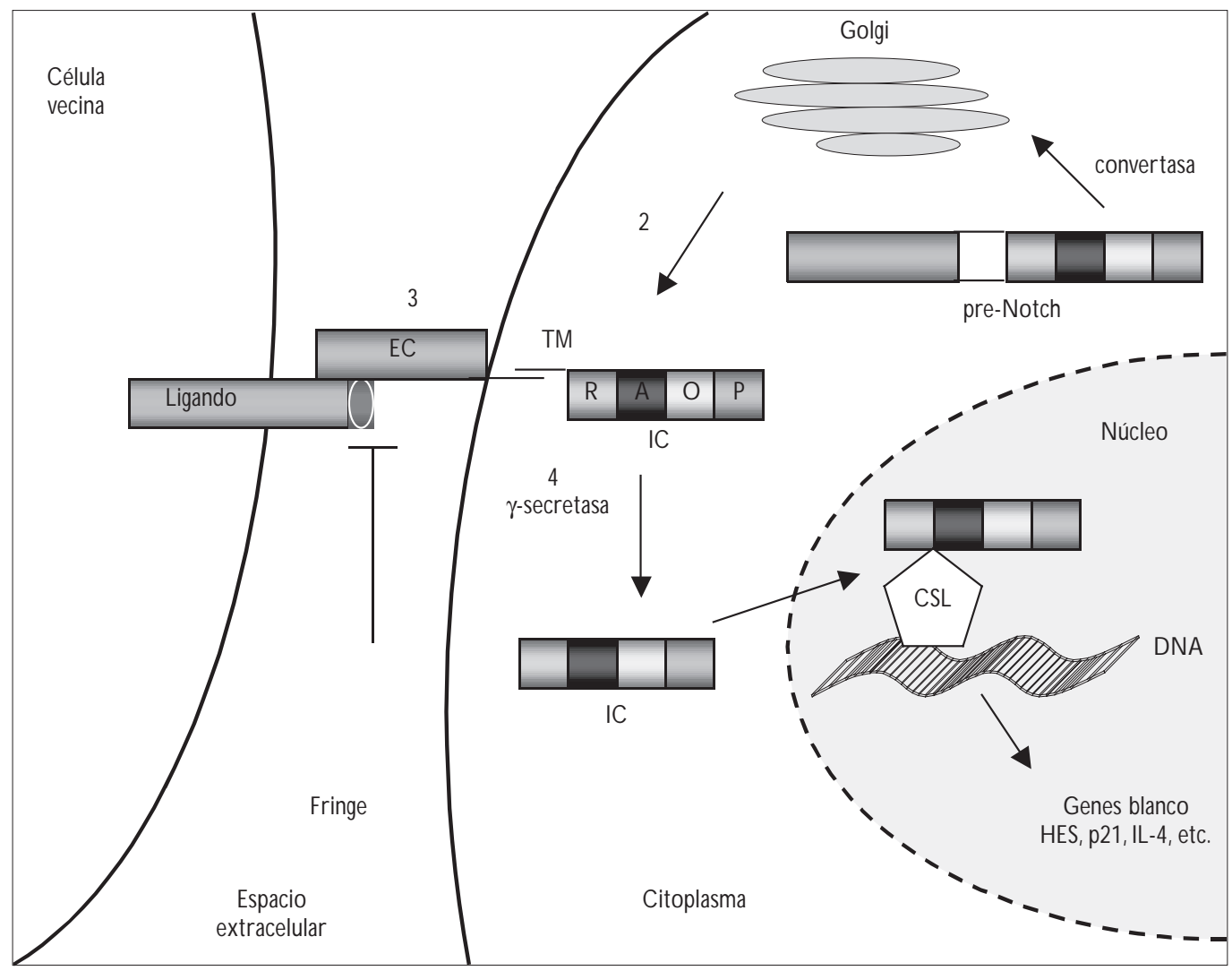

N otch se sintetiza en forma de precursor inactivo (pre-N otch) y su procesamiento en el complejo de Golgi (paso 1) es a través de hidrólisis generada por la enzima convertasa similar a Furina. El producto de esta reacción es la formación de las subunidades IC,TM y EC que se reensamblan posteriormente en la membrana plasmática (paso 2) como un complejo heterodimérico activo. La unión de Notch y su ligando (paso 3) proveniente de una célula vecina, induce el procesamiento de N otch (paso 4) por la proteína Presenilina-1 (parte del complejo enzimático gama-secretasa) liberando la subunidad intracelular IC. La translocación de IC al núcleo y su unión a factores de transcripción de la familia CSL (paso 5) da como resultado la activación de la expresión de genes específicos, esto es, los factores de transcripción HES, IL-4, N FkB, etcétera

Pre-N otch, polipéptido precursor de N otch; EC, subunidad extracelular; IC, subunidad intracelular;TM, subunidad transmembranal; R:RAM-23, sitio de alta afinidad de los factores de transcripción; A, repeticiones de Ankirina necesarias para la transmisión de señales; $0: 0$ PA, región rica en glutamina; P:PEST, región rica en prolina-glutamato-serina-treonina; CLS: CBF-1/ Lag-1/ Suppressor of Hairless

\section{Figura 1. Procesamiento del receptor Notch y mecanismo de acción}


intracitoplásmica (IC). La región EC contiene varias repeticiones en su secuencia de aminoácidos, similares a la del factor de crecimiento epidérmico (EGF-like), constituyendo las repeticiones 11 y 12 el principal sitio de unión a su ligando proveniente de otra célula.

Cuando el receptor Notch lleva a cabo la unión con su ligando en otra célula (figura 1) la subunidad transmembranal TM es procesada proteolíticamente, generando un fragmento intracelular (intracellular subunit, IC) que se transloca al núcleo e interactúa con factores de transcripción de la familia CLS (CBF-1/ Lag-1/ Suppressor of Hairless) ${ }^{6}$ a través del dominio RAM23 de IC. Al unirse CBF-1 a IC se disocia un complejo represor que incluye una diacetilasa de histonas (HDAC1) y recluta coactivadores nucleares como SKIP y MAML1 (mastermind), lo que hace a CBF-1 actuar, entonces, como un activador de la transcripción. ${ }^{7}$

Los cuatro receptores Notch en mamíferos (Notch 1-4) tienen estructuras muy similares entre sí, con diferencias esenciales en las porciones extracelular y citoplásmica. Los receptores Notch-1 y -2 contienen 36 repeticiones "EGF-like" en sus dominios EC, mientras que Notch-3 contiene 34 y Notch-4 solamente 29. A nivel del dominio IC tienen las siguientes diferencias: Notch-1 contiene un dominio de transactivación fuerte (TAD, por sus siglas en inglés), mientras que en Notch-2 su TAD es débil y en Notch-3 y -4 no está presente. ${ }^{8}$

Los ligandos del receptor Notch en invertebrados son conocidos como Delta y Serrate para D. melanogaster, en tanto que para Caenorhabditis elegans (C. elegans) se conoce LAG-1; a estos ligandos se les ha llamado colectivamente DSL. Otros ligandos en C. elegans son LAG-2, APX-1, ARG-2 y F16B12.2. En mamíferos se conoce un grupo de homólogos de Delta denominados "Delta-like"; y llamados Jagged (JAG) para Serrate. En total se conocen cinco ligandos en mamíferos denominados JAG1, JAG2 y H-Delta-1, -3, y -4 (DLL1, DLL3, y DLL4). ${ }^{9}$ En 1999, Qi y colaboradores encontraron, además, una forma soluble de Delta en Drosophila, lo que sugiere que Notch puede mediar la comunicación entre células no contiguas. ${ }^{3,10}$ Las diferencias estructurales en esta familia de ligandos son el número y el espaciamiento de las repeticiones a nivel del dominio extracelular y la presencia de un dominio rico en cisteína localizado corriente abajo de las repeticiones EGF, específicamente en los ligandos Ser, JAG1 y JAG $2{ }^{8}$

Las proteínas moduladoras de la unión receptorligando a nivel extracelular son las proteínas "Fringe" en Drosophila y sus homólogos en mamíferos, "Lunatic Fringe, Radical Fringe, y Maniac Fringe" ${ }^{11,12}$ Además, se han identificado proteínas que modulan la degradación/procesamiento de Notch a nivel intra- celular; en C. elegans se conocen las proteínas Sel-1 y Sel-10,13 y en Drosophila, la proteína Numb que actúa regulando negativamente la señalización al unirse con la región intracelular de Notch. ${ }^{14}$

Por último, los genes blanco de Notch incluyen factores de transcripción represores pertenecientes a las familias de proteínas HES (hairy and enhancer of Split) y HRT/HERP/Hey (familia "basic helix-loop-helix-Oran$\left.g e^{\prime \prime}\right), \mathrm{IL}-4, \mathrm{p} 21$, etcétera (cuadro I). Sin embargo, aún no es claro cuál(es) de esos genes es/son el/los responsables de los efectos fenotípicos de la señal Notch. Algunos ejemplos de la participación de Notch es la inhibición del desarrollo neuronal, ya que parece ser que los genes blanco Hes1 y Hes5 median muchos o quizás todos los efectos producidos por Notch. ${ }^{15} \mathrm{En}$ el caso del desarrollo del páncreas el blanco de Notch es el gen HES-1; en el desarrollo cardiaco el gen Hey2; y en el desarrollo vascular los genes Hey1 y Hey2. Notch ejerce, además, un doble papel en un modelo de cultivo celular (3T3-L1): la activación de HES-1 induce adipogénesis, mientras que al bloquear la activación de HES-1 se inhibe la diferenciación de 3T3-L1. Por último, se ha informado que el gen IL-4 es un blanco directo de Notch y explica la capacidad que tiene de promover el fenotipo Th2 de las células T de ayuda. ${ }^{16}$

En el cuadro I se muestran los elementos principales del sistema de señalización Notch y sus homólogos en distintas especies. ${ }^{17}$

\section{Localización y función de Notch}

Los estudios realizados sobre la función y localización de los receptores Notch están enfocados, primordialmente, en el receptor Notch-1, mientras que aún no se ha dilucidado el papel que desempeñan el resto de los receptores. La señalización Notch está implicada en la neurogénesis, hematopoyesis y vasculogénesis. Específicamente, Notch-2 en la morfogénesis dental, probablemente Notch-3 en neurogénesis y adipogénesis, y Notch-4 en el desarrollo vascular, renal y hepático., ${ }^{3,18-20}$

Los patrones de expresión de Notch en el desarrollo del embrión de Drosophila son bastante complejos y dinámicos. La proteína Notch se expresa, de manera amplia, en la fase temprana del desarrollo del embrión y subsecuentemente su expresión se restringe a grupos de células no comprometidas o proliferativas. En el adulto, la expresión persiste en los tejidos regenerativos de ovarios y testículos ${ }^{3,21-24}$ Estudios de Notch-1 en Xenopus muestran que sus patrones de expresión son muy similares a Drosophila, sobre todo en extirpes celulares terminalmente no diferenciadas y proliferativas. Durante el desarrollo, los tejidos con mayores niveles de expresión incluyen el cerebro, los ojos y el 
Cuadro I

Principales componentes del sistema de señalización Notch*

\begin{tabular}{|c|c|c|c|}
\hline \multirow[b]{2}{*}{ Componente } & \multicolumn{3}{|c|}{ Organismo } \\
\hline & Mamíferos & D. melanogaster & C. elegans \\
\hline \multirow[t]{4}{*}{ Receptores (N otch) } & Notch-1 (TAN -1) & Notch-1 & LIN -12 \\
\hline & Notch-2 & & GLP-1 \\
\hline & Notch-3 & & \\
\hline & Notch-4 & & \\
\hline \multirow[t]{5}{*}{ Ligandos } & D elta-like1 (DLL1) & Delta & LAG-2 \\
\hline & D elta-like3 (DLL3) & Serrate & APX-1 \\
\hline & Delta-like4 (DLL4) & & ARG -2 \\
\hline & Jagged 1 (JAG 1) & & F16B12.2 \\
\hline & \multicolumn{2}{|l|}{ Jagged 2 (JAG 2) } & \\
\hline \multirow[t]{2}{*}{ Factores de transcripción } & CBF1 (RBPJk) & Supresor de Hairless [Su(H)] & LAG-1 \\
\hline & \multicolumn{2}{|l|}{ RBPL } & \\
\hline \multirow[t]{5}{*}{ Genes blanco de N otch producto de la activación de transcripción } & p100/NF_B p21 & genes bHLH & HES \\
\hline & HES $\quad$ IL-4 & Single-minded & ESR \\
\hline & PPAR & Mastermind & \\
\hline & Ciclina D 1 & Vestigial & \\
\hline & GATA-2 $\quad$ NFkB & W ingless & \\
\hline \multirow[t]{5}{*}{ Moduladores de Notch } & Lunatic Fringe & Fringe & Sel-1 \\
\hline & Maniac Fringe & Numb & Sel-9 \\
\hline & Radical Fringe & Disheveled & Sel-10 \\
\hline & & Notchless & \\
\hline & & Deltex & \\
\hline
\end{tabular}

* Adaptado de Lai, 2004 (referencia 17)

tubo neural. ${ }^{25,26}$ Estudios en mamíferos muestran que los niveles de expresión de sus homólogos correspondientes comienzan tardíamente durante su desarrollo embrionario. Las proteínas se expresan como patrones dinámicos en tejidos que llevan a cabo la determinación del destino celular o la aceleración de la proliferación. ${ }^{27-31}$ Notch se expresa, en la fase inicial de la embriogénesis en mamíferos, en los tejidos que constituyen al mesodermo pre-somita y el neuroepitelio del embrión en desarrollo. La expresión de Notch-1 se visualiza a lo largo de todo el mesodermo pre-somita, en particular, en áreas densas a nivel del borde anterior del mesodermo. Se encontró que dicha expresión disminuye una vez que los somitas se han formado por completo e indica la posible función de Notch-1 en la diferenciación de las células precursoras de los somitas. Patrones similares del ligando Delta se observan en el desarrollo de ratón. ${ }^{31-33}$
En 2004, Balde y colaboradores caracterizaron la expresión específica de Notch-1 utilizando un arreglo de 59 tipos de tejidos normales humanos. Se demostró que Notch-1 se expresa a altas concentraciones en una amplia variedad de tejidos en el epitelio estratificado de la epidermis y en capas suprabasales intermedias de las mucosas de la cavidad oral, esófago, ectocérvix y vagina. Se observaron niveles intermedios a bajos en linfocitos de algunos tejidos linfoides periféricos, particularmente en centros germinales de nódulos linfáticos. ${ }^{34}$

La función de la señalización Notch involucra una gran variedad de procesos celulares incluyendo el mantenimiento de células troncales, especificación del destino celular, diferenciación, proliferación y apoptosis, por lo que posee efectos pleiotrópicos en diferentes órganos. Los tres efectos principales son: a) el mantenimiento de las células troncales o precursoras en un estado no diferenciado; b) la influencia en las 
decisiones del destino celular, ya sea a través de la vía lateral o bien por una vía inductora dependiente de la cantidad de receptor-ligando expresado en la membrana, y c) la habilidad de influenciar la diferenciación y la progresión del ciclo celular. ${ }^{8,35}$ Ejemplo de ello es el sistema nervioso, en el cual Notch promueve la diferenciación de varios tipos celulares de la glia incluyendo astrocitos, células de Schwann, células de Müller y células radiales. ${ }^{36}$

La señalización Notch juega un papel excepcionalmente interesante en la diferenciación de la epidermis, ya que al parecer tiene una función opuesta a los efectos antes descritos. En queratinocitos, la señalización Notch estimula la expresión de marcadores de diferenciación y reduce la proliferación celular a través de la activación de Notch-1. Estudios en ratones apoyan un modelo de Notch-1 en piel que promueve la diferenciación celular en vez de suprimirla y, adicionalmente, estos ratones son más susceptibles al desarrollo de tumores a nivel basal. ${ }^{37,38}$

En el sistema inmune, Notch se encuentra involucrado en el proceso de maduración de las células $\mathrm{T}$ en el timo que expresarán los receptores CD4 o CD8, además del receptor TCR. Durante este proceso, las células doblemente negativas (CD4-CD8') expresan altas concentraciones de Notch-1; después, las células doble positivas $\left(\mathrm{CD}^{+}{ }^{+} \mathrm{CD} 8^{+}\right)$presentan una disminución de Notch-1, y posteriormente, su concentración es intermedia en las células maduras que son positivas para $\mathrm{CD}^{+}{ }^{+} \mathrm{oCD} 8^{+}$. Estos datos sugieren que Notch-1 desempeña un papel clave en la determinación tanto del linaje $\mathrm{CD} 4 / \mathrm{CD} 8$, en la determinación de la expresión del receptor TCR ab vs. gd, así como también en la regulación de la muerte celular de células T.39,40

\section{Notch y enfermedad}

Los componentes de la vía Notch están involucrados en una gran variedad de enfermedades humanas, siendo la más frecuente el cáncer. Entre las causas principales se encuentran la presencia de mutaciones, deleciones, translocaciones e inserciones virales en sus genes.

Estudios durante el desarrollo embrionario del ratón han revelado la conexión entre mutaciones de los genes Notch y la presencia de síndromes de enfermedades congénitas humanas, como se describe a continuación.

El gen humano notch-1 se detectó por primera vez en el subtipo de leucemia linfoblástica aguda de las células T (T-LLA, por sus siglas en inglés) al producirse una translocación cromosomal $(7 ; 9)$ (q34;q34.3). ${ }^{41}$ Este rearreglo origina la expresión de Notch-1 con las porciones TM e IC y excluye la porción EC. Hallazgos recientes describen que más de $50 \%$ de los casos con T-LLA presentan mutaciones activantes que involucran específicamente al dominio de heterodimerización extracelular o del carboxilo terminal del dominio PEST de notch-1. ${ }^{42}$

Otros ejemplos de mutaciones incluyen la tetralogía de Fallot, que involucra una mutación puntual (G274D) y expresa al ligando JAG-1 en sentido erróneo. Esta enfermedad se caracteriza por estenosis y atresia pulmonar, y ausencia de la válvula pulmonar. El síndrome de Alagille se debe a diferentes mutaciones en $J A G-1$ y provoca al menos $72 \%$ de codones de terminación prematuros. Desarrolla anormalidades en el hígado, corazón, ojos y esqueleto, principalmente. La disostosis espondilocostal (o síndrome de Jarcho-Levin), es un defecto de segmentación vertebral múltiple con alteraciones costales ocasionado por mutaciones en el ligando DLL3 y provoca su expresión en forma truncada. ${ }^{43}$ Finalmente, CADASIL (Cerebral Autosomal Dominant Arteriopathy with Subcortical Infarcts and Leukoencephalopathy), es una enfermedad cerebrovascular hereditaria que ocasiona un declive cognitivo y demencia. Se trata de una enfermedad vascular sistémica que afecta pequeños vasos y se transmite de forma autosómica dominante. La enfermedad está ligada a una mutación del gen Notch-3 en el punto cromosómico 19p13, proteína relacionada, además, con la diferenciación de los adipocitos durante el desarrollo. ${ }^{44}$

\section{Implicaciones de Notch en cáncer y apoptosis}

En consideración a que la señalización Notch controla críticamente las decisiones del destino celular en numerosos tejidos y en diversos tiempos de la diferenciación, es razonable pensar que cualquier desregulación de la función de Notch pudiera estar involucrada con el desarrollo de cáncer.

En los últimos años se ha notificado sobreexpresión de componentes de la vía Notch en una gran variedad de carcinomas humanos, incluyendo leucemias, neuroblastomas, cáncer cervicouterino $(\mathrm{CaCu})$, cáncer de mama, tumores mucoepidermoides, carcinomas renales, cáncer de piel y cáncer pulmonar, entre otros.

La leucemia T-LLA, que expresa la forma truncada de Notch-1, tiene como resultado la expresión constitutiva y activa de Notch-1 y acarrea el arresto de los linfoblastos T durante la maduración en el estadío en que las células $\mathrm{CD} 4^{+} \mathrm{CD} 8^{+}$son doble positivas. Este evento correlaciona perfectamente el desarrollo de TLLA, ya que potencialmente Notch-1 posee una actividad transformante para permitir la sobrevivencia de las células doble positivas que, de otra manera, esta- 
rían destinadas al suicidio celular (apoptosis). ${ }^{42,45}$ Experimentalmente se observa que Notch-1 (antes conocido como TAN-1, translocation-associated Notch homologue), sostiene una interacción directa entre su porción IC y el factor transcripcional Nur77 en el núcleo, dando lugar a la inhibición de la apoptosis en hibridoma de células T (línea DO11.10). ${ }^{46}$ Asimismo, la expresión del fragmento IC de Notch inhibe la apoptosis inducida por dexametasona en células de linfoma y en hibridomas de células T. Se ha sugerido que la proteína SGR3, un regulador de la transcripción que participa en la remodelación de la cromatina en procesos de desarrollo, proliferación y diferenciación celular, es blanco de la señalización Notch al conferir resistencia a glucocorticoides en timocitos. ${ }^{47}$

En 1998, Deftos y colaboradores observaron la sobreexpresión de la proteína anti-apoptótica Bcl-2 en una línea celular de linfoma tímico (AKR1010) al inducir la expresión de la forma activa de Notch- $1 .{ }^{40}$

Otros estudios in vitro han detectado, además, genes truncados de Notch-1 y Notch-2 (en la subunidad IC) que le atribuye una actividad transformante a células de riñón de rata. ${ }^{48}$

Alteraciones que causan la desregulación de la vía Notch en otras especies son, por ejemplo, la inserción del virus de leucemia murina Moloney (M-MLV) en la región transmembranal del gen Notch-1, o bien la excisión e integración del virus de leucemia felina (FeLV) en el extremo 3' del gen Notch-2. Ambos cambios pro- ducen ganancia de la función de ambos receptores y, como consecuencia, efectos antiapoptóticos. ${ }^{49,50}$

Por otra parte, también se ha documentado mutagénesis insercional en el genoma de ratón del retrovirus MMTV (Mouse Mammary Tumor Virus) en tumores mamarios. El sitio de integración más frecuente, int-3, está localizado dentro de la región del gen Notch-4. La expresión de la oncoproteína int-3/Notch-4 transforma a células epiteliales mamarias en ensayos murinos. ${ }^{35}$

Las evidencias antes descritas indican que el sistema de señalización Notch se encuentra íntimamente relacionado con la tumorigénesis y la apoptosis; sin embargo, existen pruebas sustentadoras de que esta vía no es solamente oncogénica, sino que, además, funciona como un supresor de tumores. Tal es el caso en cáncer cervicouterino $(\mathrm{CaCu})$, como se describe a continuación. En el cuadro II se resumen las funciones potenciales de Notch en cáncer. ${ }^{51}$

\section{Cáncer cervicouterino y Notch}

Dado que el sistema de señalización Notch permite mantener a las células un estado proliferativo o indiferenciado, se piensa que su papel en cáncer es prevenir la respuesta de las células neoplásicas a la señal de diferenciación. Ya que las oncoproteínas virales contribuyen al proceso de tumorigénesis, el elemento faltante para llevar a cabo la transformación celular es la desregulación de Notch.

\section{Cuadro II \\ Funciones potenciales de la señalización Notch en CÁncer*}

\begin{tabular}{|c|c|c|}
\hline Función & Mecanismo & Contexto celular \\
\hline O ncoproteína & $\begin{array}{l}\text { Ganancia de función independiente de ligando } \\
\text { Ganancia de función dependiente de ligando }\end{array}$ & $\begin{array}{l}\text { Células pre-T } \\
\text { Línea celular RKE } \\
\text { Epitelio mamario murino (vía inserción retroviral) } \\
\text { Células Reed-Sternberg (linfoma Hodgkin) y linfoma } \\
\text { anaplásico de células gigantes } \\
\text { Células mesoteliales (con SV40) } \\
\text { Células pre-T (en ratones sobreexpresando D LL-4) }\end{array}$ \\
\hline Supresor de tumores & Pérdida de función & $\begin{array}{l}\text { Q ueratinocitos } \\
\text { Posiblemente otros epitelios escamosos }\end{array}$ \\
\hline Factor metaplásico & Activación dependiente de ligando & $\begin{array}{l}\text { Células acinares de páncreas } \\
\text { Endocérvix }\end{array}$ \\
\hline 'Angiogénesis & Activación dependiente de ligando & Células endoteliales \\
\hline Renovación de células troncales cancerosas & Activación dependiente de ligando & Población auto-regenerante de células progenitoras \\
\hline Respuesta inmune & Activación dependiente de ligando & $\begin{array}{l}\text { Células dendríticas } \\
\text { Células T de sangre periférica }\end{array}$ \\
\hline
\end{tabular}

*A daptado de W eng y Aster, 2004 (referencia 51) 
$\mathrm{El} \mathrm{CaCu}$ es la segunda causa de mortalidad en mujeres en el mundo y es uno de los tipos de cáncer más estudiado en relación con la vía Notch. Se afirma que la infección por el virus del papiloma humano (VPH) contribuye al desarrollo de esta enfermedad en $99 \%{ }^{52} \mathrm{El}$ primer estudio realizado sobre Notch en $\mathrm{CaCu}$ en humano señala que su expresión está asociada a poblaciones celulares específicas: células escamosas del cérvix en carcinomas in situ e invasivos. Se observó, además, que la distribución subcelular de Notch-1 cambia en la medida en que la enfermedad progresa de preneoplasia (NIC3), con altas concentraciones de Notch-IC en el citoplasma a altas concentraciones de Notch-IC en el núcleo en carcinomas microinvasivos.*

La transformación no se ha confirmado en tumores que progresan en forma natural, sino sólo al inducir in vitro la expresión simultánea de Notch-IC y oncoproteínas como E1A de adenovirus, E6 y E7 de VPH, RAS, MYC, o el antígeno T del virus de simio 40 (SV40T). Estas oncoproteínas tienen la propiedad de anular el punto de control G1-S del ciclo celular. Por lo tanto, no es probable que la contribución de Notch en tumorigénesis sea la de revocar este punto de control, sino más bien la de proveer de características oncogénicas a las células, tal como lo es la resistencia a apoptosis, anoikis, o diferenciación. ${ }^{8}$

Para explicar las aseveraciones antes descritas, se estudió el papel que desempeña la expresión espontánea de Notch-1 en CaCu. Se llevaron a cabo estudios de silenciamiento de Notch-1 a través de siRNA (small interfering $R N A$ ) e inhibición farmacológica de la enzima g-secretasa. Ambos experimentos muestran que la susceptibilidad de las células transformadas de $\mathrm{CaCu}$ se incrementa en gran medida al tratarlas simultáneamente con altas concentraciones de cisplatino (tratamiento sistémico de uso cotidiano en pacientes con $\mathrm{CaCu}$ ), al activar a la caspasa $3 \mathrm{y}$, como consecuencia, la inducción a apoptosis. Los resultados indican que el efecto primario de Notch-1 en CaCu es el de transducir una señal de supervivencia. En resumen, estos datos apoyan el modelo en el cual la expresión sostenida y endógena de Notch-1 protege a las células cancerosas de la inducción a apoptosis y, por lo tanto, puede ser explotado como blanco potencial en el tratamiento de $\mathrm{CaCu} .{ }^{53}$

\footnotetext{
* Song LL, Vijaya Chaturvedi V, Mascarenhas J, Sanne Weijzen S, Kast WM, Santos L, et al. Endogenous Notch-1 inhibits apoptosis in cervical cancer cells by non-transcriptional activation of NF-kB via the PI3 kinase-AKT pathway. Cancer Res (sometido 2005).
}

\section{Notch y terapia del cáncer}

En resumen, los estudios reconocen al sistema de señalización Notch como un blanco modelo para el desarrollo de fármacos en la erradicación de cáncer y otras enfermedades. A continuación se describen algunos ejemplos con propósitos biofarmacéuticos, específicamente antagonistas (inhibidores) y agonistas de la vía Notch y, por último, sus aplicaciones potenciales en cáncer.

Dentro de los inhibidores experimentales, se han desarrollado proteínas recombinantes y anticuerpos monoclonales dirigidos contra las repeticiones 11 y 12 de la región EC de Notch (rh11-12), que es el sitio de unión de Notch con su ligando. ${ }^{54}$ La ventaja de desarrollar proteínas recombinantes de este tipo es que son fáciles de expresar, tienen un peso relativamente pequeño (aproximadamente $10 \mathrm{kDa}$ ) y, por lo tanto, es probable una biodistribución extravascular eficiente. Una desventaja de este tipo de moléculas es el tamaño, ya que éste permite una rápida eliminación a través del riñón y, por ende, un tiempo de vida corto. Es posible que se llegue a producir una proteína de fusión que contenga la región Fc de inmunoglobulina, incrementando así su masa molecular y biodistribución, como en el caso del receptor del factor de necrosis tumoral (p75 TNF). ${ }^{55}$

Otra alternativa es el uso de derivados biofarmacéuticos a nivel de la proteína Fringe. Estas son proteínas secretoras extracelulares que modulan las interacciones entre Notch-ligando en Drosophila (figura 1). Se ha sugerido el uso de proteínas recombinantes Fringe para modular la señalización Notch en humano. ${ }^{2,56,57}$

En el caso de agentes antisentido, Austin y colaboradores utilizaron oligonucleótidos antisentido dirigidos contra tres regiones diferentes del RNAm de Notch-1 para reducir la expresión de Notch-1 en cultivos de células precursoras de retina de pollo (método propuesto por Altshuler y Cepko, 1992). Estas regiones son: a) la región EGF-like; b) la región lin12/Notch del dominio extracelular, y c) la región cdc/ankirina de la región intracelular de Notch. El efecto es la aceleración en la diferenciación de células precursoras ganglionares. ${ }^{58}$

Por otro lado, la transfección de un oligonucleótido antisentido dirigido contra los residuos de ankirina en la porción Notch-IC en células 3T3L1, inhibe por completo la expresión de Notch- $1 .{ }^{54}$

Shelly y colaboradores han logrado inducir apoptosis en células eritroleucémicas murinas (MEL) mediante la utilización de oligonucleotidos antisentido, o bien, forzando la expresión de RNAm antisentido durante la diferenciación con el fármaco Hexametile- 
no-Bisacetamida (HMBA). Esta estrategia causa que las células MEL abandonen el programa de diferenciación para sufrir apoptosis espontánea. ${ }^{59}$

Una ventaja adicional del uso de oligonucleótidos antisentido dirigidos contra Notch podría ser la capacidad de hacer blanco específico en las fracciones extracelular (EC) e intracelular de Notch (IC) en la activación o modulación, respectivamente.

La presenilina-1 (PS-1 es una proteína que forma parte del complejo enzimático gama-secretasa (paso 4, figura 1). Se han utilizado agentes farmacológicos inhibidores de PS-1 para prevenir la hidrólisis en la fracción TM de Notch inducida por ligando. Weng y colaboradores probaron 12 diferentes inhibidores de la PS-1, y encontraron que un derivado de las benzodiazepinas, el DFP-AA, causa supresión del crecimiento de las células T6E (línea celular leucémica-linfoblástica de células T) en concentraciones nanomolares. ${ }^{45}$

En el caso del uso de agonistas, se han desarrollado formas recombinantes in vitro del ligando JAG-1, así como un péptido sintético derivado del mismo. Este péptido está formado por los residuos 188-204 de la región DSL altamente conservada de JAG-1 y -2 e inhibe la diferenciación inducida en la línea celular mieloide 32D que expresa Notch-1..$^{60,61}$ No obstante, cabe mencionar que los péptidos activos como el anterior están diseñados en regiones que contienen altos contenidos de cisterna, por lo que pueden formar estructuras plegadas para su estabilización a través de puentes disulfuro. Estas características son desventajosas dado que se puede llevar a cabo oxidación y formación de puentes disulfuro al azar, y agregación y pérdida de actividad biológica durante el almacenamiento. Se podría optimizar el diseño de tales agonistas sustituyendo los residuos de cisteína por otros aminoácidos con el uso del "diseño racional" ${ }^{62}$ Se han sugerido mezclas de agonistas/antagonistas en la línea celular S2 de Drosophila (expresión de proteínas heterólogas). ${ }^{60}$ Dependiendo de las afinidades relativas ligando-ligando y ligando-receptor, sería posible el uso de ligandos solubles que puedan secuestrar moléculas de ligando, formando así complejos homotípicos (e.g. Delta-Delta) y reduciendo la concentración de moléculas de ligando disponibles para unirse a Notch. Al utilizar concentraciones más altas, una vez que los ligandos endógenos estén saturados, sería posible observar el efecto agonista del ligando exógeno libre para interactuar con Notch. Con base en la dosis, este modelo podría predecir el efecto agonista o antagonista de un ligando soluble. El uso clínico de los ligandos recombinantes de Notch y de los péptidos sintéticos estará determinado por consideraciones farmacológicas como la farmacocinética, el volumen de distribución, el acceso a compartimentos extracelulares, etcétera. ${ }^{56}$

En el caso de la terapia génica, se podrían usar los mediadores de Notch (e.g. Deltex) para alcanzar una activación inducible de los factores de transcripción y producir un efecto parcial parecido al de Notch. En la naturaleza, el virus Epstein-Barr usa este efecto. La proteína viral EBNA2 mimetiza la señalización Notch al convertir al represor transcripcional CBF-1 en su forma activante. ${ }^{63}$

El desarrollo de los agentes antineoplásicos basados en las estrategias experimentales antes mencionadas requerirá, además de estudios enfocados a los efectos sistémicos adversos, el desarrollo de liberación del fármaco de forma que permitan mayor especificidad sobre un determinado órgano blanco.?

\section{Discusión}

En la actualidad, sólo 2 a 4\% de los casos con cáncer en el mundo responden a la quimioterapia. Por otra parte, estos agentes farmacológicos producen graves efectos secundarios, además de tener una efectividad limitada. Por ejemplo, los derivados del platino (cisplatino, carboplatino, oxaliplatino, entre otros) se utilizan en el tratamiento en una amplia variedad de tumores malignos de ovario, cuello del útero, pulmón, testículo, vejiga, mama, próstata, piel, páncreas, etcétera. Su efectividad está basada en la habilidad para formar complejos con el ADN, a fin de inducir la muerte celular programada. No obstante, son responsables de efectos colaterales severos irreversibles de tipo nefrotóxico y ototóxico, lo que representa un obstáculo para extender su uso. Es por ello que la introducción de nuevas estrategias para mejorar la eficacia y especificidad en el tratamiento del cáncer se hace necesaria.

Las evidencias presentadas indican que el sistema de señalización Notch está frecuentemente desregulado en cáncer $\mathrm{y}$, por lo tanto, su modulación ofrece una nueva estrategia terapéutica. Los estudios sobre la vía de señalización Notch han revelado la importancia de su función al controlar las decisiones del destino celular, incluyendo eventos en el desarrollo, renovación de células troncales y diferenciación en diversos tejidos. Con el objeto de regular la señalización Notch en condiciones patológicas, se ha considerado el uso de proteínas recombinantes, péptidos sintéticos, anticuerpos monoclonales, oligonucleótidos antisentido y terapia génica, mismo que significa un campo de investigación prometedor para la industria biofarmacéutica en el desarrollo de agentes antineoplásicos. 
El enfoque de la terapia génica en cáncer representa una tecnología emergente como nueva opción de tratamiento. El uso de adenovirus oncolíticos es especialmente prometedor, ya que éstos pueden replicarse selectivamente en células tumorales, teniendo como blanco lesiones inherentes en cáncer, o la incorporación de promotores específicos de tejido que sometan a los genes tempranos a iniciar la replicación viral. ${ }^{64}$ La terapia con adenovirus oncolíticos ha mostrado los mejores resultados y logra un efecto tumoricida aumentado cuando se utiliza en combinación con agentes quimioterapeúticos en bajas dosis como el cisplatino, la leucovorina y el 5'-fluoracilo. Además, las formulaciones de liposomas con genes como Notch podrían superar barreras en las aplicaciones de terapia génica en un escenario clínico. ${ }^{66}$ Estos estudios se han utilizado ampliamente en cultivos celulares y en animales transgénicos para activar el sistema de señalización Notch. Sin embargo, al utilizar formas variantes de los receptores Notch, se induce a una actividad transformante junto con algunos virus oncogénicos, ${ }^{64} \mathrm{y}$ además se ocasionan linfomas de células $\mathrm{T}$ cuando se introducen en células hematopoyéticas progenitoras de ratón. ${ }^{65}$ De este modo, es obvio que el uso potencial de variantes de Notch expresados constitutivamente para la terapia génica implica un gran número de aspectos de bioseguridad, aun usando vectores inducibles. La alternativa más razonable es mimetizar funciones de Notch a través de proteínas virales como se mencionó anteriormente. No obstante, se desconoce si esta estrategia implica los mismos desafíos que representa la expresión constitutiva y activa de Notch.

Las vías potenciales indirectas que podrían utilizarse para regular positivamente a la señalización Notch son: a) la inhibición del supresor de la degradación/ubiquitinación del receptor mediado por Deltex, o b) la regulación negativa de los moduladores de la actividad de Notch como la proteína Notchless o Numb. Estas dos opciones podrían llevarse a cabo mediante el método antisentido o también a través de fármacos sintéticos permeables a la célula que inactiven estos blancos.

El desafío actual es llevar estas estrategias probadas experimentalmente in vitro e in vivo a una etapa posterior, es decir, a estudios pre-clínicos farmacológicos con la finalidad de evaluar el costo-riesgo-beneficio. El primer paso lo ha dado la compañía Viragen, Inc. (patentes no. 60/102,816,09/806,440, y 60/124,119), donde se explota la tecnología de los anticuerpos monoclonales para inducir apoptosis en células tumorales utilizando específicamente al receptor Notch-1, para los cuales consideran al cáncer cervicouterino, cáncer de mama y cáncer pulmonar.

\section{Agradecimientos}

Se agradece al doctor Rubén H. López-Revilla, Jefe de la División de Biología Molecular del Instituto Potosino de Investigación Científica y Tecnológica A.C. (IPICyT) su valiosa ayuda en la discusión y preparación de este manuscrito.

\section{Referencias}

1. Morgan, TH.The theory of the gene. Am N at 1917; 51:513-544. 2.W u JY, Rao Y. Fringe: D efining borders by regulating the $\mathrm{N}$ otch pathway. Curr 0 pin N eurobiol 1999; 9:537-543.

3.W harton KA, Johansen KM, X U T,Artavanis-T sakonas S. N ucleotide sequence from the neurogenic locus notch implies a gene product that shares homology with proteins containing EG F-like repeats. Cell 1985; 43:567-581.

4.Artavanis-T sakonas S, Rand MD, Lake RJ. N otch signaling: C ell fate control and signal integration in development. Science 1999;284:770-776. 5. Kidd S, Kelley MR, Young MW. Sequence of the notch locus of Drosophila melanogaster: Relationship of the encoded protein to mammalian clotting and growth factors. Mol C ell Biol 1986; 6:30943108.

6. Tamura K, TaniguchiY, Minoguchi S, Sakai T, Tun T, H onjo T, et al. Physical interaction between a novel domain of the receptor $\mathrm{N}$ otch and the transcription factor RBP-Jk/Su(H). Curr Biol 1995; 5:1416-1423. 7. N ickoloff BJ, O sborne BA, Miele L. N otch signaling as a therapeutic target in cancer:A new approach to the development of cell fate modifying agents. 0 ncogene 2003; 22:6598-6608.

8. Radtke F, Raj K. The role of $\mathrm{N}$ otch in tumorigenesis: 0 ncogene or tumour suppressor? N at Rev Cancer 2003; 3:756-767.

9. Gray GE, Mann RS, Mitsiadis E, Henrique D, C arcangiu ML,ArtavanisTsakonas S. Human ligands of the N otch receptor. Am J Pathol 1999; 154:785-794.

10. Q i H, Rand MD, W u X, Sestan N,W angW, Rakic P, et al. Processing of the notch ligand delta by the metalloprotease Kuzbanian. Science 1999; 283:91-94.

11. Moran JL, Johnston SH, Rauskolb C, Bhalerao J, Bowcock AM,Vogt TF. Genomic structure, mapping, and expression analysis of the mammalian Lunatic, Maniac, and Radical fringe genes. Mamm Genome 1999; 10:535-541. 12. Johnston SH, Rauskolb C, W ilson R, Prabhakaran B, Irvine KD, Vogt TF.A family of mammalian Fringe genes implicated in boundary determination and the N otch pathway. D evelopment 1997; 124: 2245-2254.

13. Sundaram M, G reenwald I. Suppressors of a lin-12 hypomorph define genes that interact with both lin-12 and glp-1 in Caenorhabditis elegans. Genetics 1993; 135:765-783.

14. Spana EP, D oe CQ . N umb antagonizes N otch signaling to specify sibling neuron cell fates. N euron 1996; 17:21-26.

15. 0 htsuka T, Ishibashi M, G radwohl G, N akanishi S, G uillemot F, Kageyama R. Hes1 and Hes5 as notch effectors in mammalian neuronal differentiation. EMBO J 1999; 18:2196-2207.

16. Kadesch T. N otch signaling: the demise of elegant simplicity. Curr 0 pin Genet Dev 2004; 14:506-512.

17. Lai EC. N otch signaling: control of cell communication and cell fate. D evelopment 2004; 131:965-973.

18. Bigas A, Martin DIK, Milner LA. N otch1 and N otch2 inhibit myeloid differentiation in response to different cytokines. Mol Cell Biol 1998; 18:2324-2333 
19. Uyttendaele H, Ho J, Rossant J, Kitajewski J.Vascular patterning defects associated with expression of activated $\mathrm{N}$ otch4 in embryonic endothelium. Proc N atl A cad Sci U SA 2001; 98:5643-5648.

20. Mitsiadis TA, Regaudiat L, Gridley T. Role of the N otch signalling pathway in tooth morphogenesis. Arch 0 ral Biol 2005; 50:137-140. 21. Fortini ME,Artavanis-T sakonas S. N otch: N eurogenesis is only part of the picture. Cell 1993; 75:1245-1257.

22. Jan $Y N$, Jan $L Y$. Functional gene cassettes in development. Proc $\mathrm{N}$ atl Acad Sci U SA 1993; 90:8305-8317.

23. G reenwald I. Structure/function studies of lin- $12 / \mathrm{N}$ otch proteins. Review. Curr O pin Genet Dev 1994; 4:556-562.

24. Artavanis-T sakonas S, Matsuno K, Fortini ME. N otch signaling. Science 1995; 268:225-232.

25. C offman C, Harris W, Kintner C. X otch, the Xenopus homolog of Drosophila notch. Science 1990; 249:1438-1441.

26. Bierkamp C, C ampos-0 rtega JA. A zebrafish homologue of the Drosophila neurogenic gene $\mathrm{N}$ otch and its pattern of transcription during early embryogenesis. Mech D ev 1993; 43:87-100.

27. W einmaster G, Roberts VJ, Lemke G.A homolog of Drosophila N otch expressed during mammalian development. D evelopment 1991; 113:199-205

28. Lardelli M, Dahlstrand J, Lendahl U. The novel N otch homologue mouse N otch 3 lacks specific epidermal growth factor-repeats and is expressed in proliferating neuroepithelium. Mech Dev 1994; 46:123-136. 29. Stifani S, Blaumueller CM, Redhead N J, Hill RE,Artavanis-Tsakonas S. Human homologs of a Drosophila Enhancer of split gene product define a novel family of nuclear proteins. $N$ at G enet 1992; 2:119-127. 30. Kopan $\mathrm{R}, \mathrm{W}$ eintraub $\mathrm{H}$. Mouse notch: Expression in hair follicles correlates with cell fate determination.J C ell Biol 1993; 121:631-641. 31. Horvitz HR, Sternberg PW . Multiple intercellular signalling systems control the development of the Caenorhabditis elegans vulva. $N$ ature 1991; 351:535-541.

32. Reaume AG, Conlon RA, Zirngibl R, Yamaguchi TP, Rossant J. Expression analysis of a $\mathrm{N}$ otch homologue in the mouse embryo. Dev Biol 1992; 154:377-387.

33. Benedito R, Duarte A. Expression of D\|4 during mouse embryogenesis suggests multiple developmental roles. Gene Expr Patterns 2005;5:750-755

34. Baldi A, De Falco M, De Luca L, C ottone G, Paggi MG, N ickoloff B], et al. Characterization of tissue specific expression of $\mathrm{N}$ otch-1 in human tissues. Biol C ell 2004; 96:303-311.

35. Miele L, $O$ sborne B.Arbiter of differentiation and death: $N$ otch signaling meets apoptosis. J Cell Physiol 1999; 181:393-409.

36. ids $=11506867 \&$ query_hl=20" Lundkvist J, Lendahl U. N otch and the birth of glial cells. Trends N eurosci 2001; 24:492-504.

37. Rangarajan A,Talora C, 0 kuyama R, $\mathrm{N}$ icolas $\mathrm{M}$, Mammucari $\mathrm{C}, \mathrm{O}$ h H, et al. $N$ otch signaling is a direct determinant of keratinocyte growth arrest and entry into differentiation. EMBO J 2001; 20:3427-3436. 38. N icolas M, W olfer A, Raj K, Kummer JA, Mill P, van N oort M, et al. $\mathrm{N}$ otchl functions as a tumor suppressor in mouse skin. $\mathrm{N}$ at $\mathrm{Genet}$ 2003: 33:416-421.

39. Hasserjian RP,Aster JC, D avi F,W einberg DS, Sklar J. Modulated expression of notch: 1 during thymocyte development. Blood 1996; 88:970-976.

40. D eftos ML, HeYW, 0 jala EW, Bevan MJ. Correlating notch: signaling with thymocyte maturation. Immunity 1998; 9:777-786.

41. Ellisen LW, Bird J,W est DC, Soreng AL, Reynolds TC , Smith SD, et al. TAN -1, the human homolog of the Drosophila notch gene, is broken by chromosomal translocations in T lymphoblastic neoplasms. C ell 1991; 66:649-661.

42. Pear W S,Aster JC.T cell acute lymphoblastic leukemia/lymphoma:A human cancer commonly associated with aberrant $\mathrm{N}$ otch 1 signaling. Curr 0 pin Hematol 2004; 11:426-433.
43. G ridley T. N otch signaling and inherited disease syndromes. Hum Mol Genet 2003; 12:R9-13.

44. Kalimo H,Viitanen M, Amberla K, Juvonen V, Marttila R, Poyhonen M, et al. CADASIL: Hereditary disease of arteries causing brain infarcts and dementia. N europathol Appl N eurobiol 1999;25:257-265.

45. W eng AP, N am Y, W olfe MS, Pear W S, G riffin JD, Blacklow SC, et al. Growth suppression of Pre-T acute limphoblastic leucemia cells by inhibition of $\mathrm{N}$ otch signaling. Mol Cell Biol 2003;23:655-664.

46. Jehn BM, Bielke W, Pear W S, 0 sborne BA. C utting edge: Protective effects of N otch-1 on TCR-induced apoptosis. J Immunol 1999; 162:635-638.

47. Young IC, Jeon SH, Jang J, H an S, Kim JK, C hung H, et al. N otch 1 confers a resistance to glucocorticoid-induced apoptosis on developing thymocytes by down-regulating SRG 3 expression. Proc $N$ atl Acad Sci U SA 2001;98:10267-10272.

48. Capobianco AJ, Zagouras P, Blaumueller CM, Artavanis-T sakonas S, Bishop JM. N eoplastic transformation by truncated alleles of human N OTCH1/TAN 1 and N OTCH2. Mol Cell Biol 1997;17:6265-6273. 49. Girard L, Hanna Z, Beaulieu N, Hoemann CD, Simard C, Kozak CA, et al. Frequent provirus insertional mutagenesis of $\mathrm{N}$ otchl in thymomas of MMTVD/myc transgenic mice suggests a collaboration of c-myc and N otch1 for oncogenesis. Genes Dev 1996;10:1930-1944.

50. Rohn JL, Lauring AS, Linenberger ML, 0 verbaugh J.Transduction of $\mathrm{N}$ otch2 in feline leukemia virus-induced thymic lymphoma. JVirol 1996; 70:8071-8080

51. Weng AP,Aster JC. Multiple niches for $\mathrm{N}$ otch in cancer: Context is everything. Curr 0 pin Genet Dev 2004;14:48-54.

52.W alboomers JM, Jacobs MV, Manos M M, Bosch FX, Kummer JA, Shah $\mathrm{KV}$, et al. Human papillomavirus is a necessary cause of invasive cervical cancer worldwide.J Pathol 1999;189:12-19.

53. Zagouras P, Stifani S, Blaumueller CM, C arcangiu ML,ArtavanisTsakonas S. Alterations in $\mathrm{N}$ otch signaling in neoplastic lesions of the human cervix. Proc N atl A cad Sci U SA 1995:92:6414-6418.

54. Song LL,VijayaV, Mascarenhas J, Sanne W eijzen S, Kast W M, Santos L, et al. Endogenous $\mathrm{N}$ otch-1 inhibits apoptosis in cervical cancer cells by non-transcriptional activation of N F-KB via the PI3 kinase-AKT pathway. Cancer Res 2005 (sometido).

54. Garcés C, Ruiz-Hidalgo MJ, Font de Mora J, Park C, Miele L, Goldstein J, et al. Notch-1 controls the expression of fatty acidactivated transcription factors and is required for adipogenesis. J Biol Chem 1997; 272:29729-29734

55. Murray KM, D ahl SL. Recombinant human tumor necrosis factor receptor ( $p 75) \mathrm{Fc}$ fusion protein (TN FR:Fc) in rheumatoid arthritis.Ann Pharmacother 1997; 31:1335-1338.

56. Fleming RJ,Yi G, Hukriede N A. Serrate-mediated activation of $N$ otch is specifically blocked by the product of the Fringe gene in the dorsal compartment of the Drosophila wing imaginal disc. D evelopment 1997; 124: 2973-2981.

57. Zlobin A, Jang M, Miele L. Toward the rational design of cell fate modifiers: $N$ otch signaling as a target for novel biopharmaceuticals. Curr Pharm Biotechnol 2000; 1:83-106.

58. A ustin CP, Feldman DE, Ida JA Jr, Cepko CL.Vertebrate retinal ganglion cells are selected from competent progenitors by the action of N otch. Development 1995; 121:3637-3650.

59. Shelly LL, Fuchs C, Miele L. N otch inhibits apoptosis in murine erithroleukemia cells and it is necessary for differentiation induced by hybrid polar compounds. J Cell Biochem 1999; 73: 164-175.

60. Li L, Milner LA, D engY, Iwata M, Banta A, G raf L, et al.The human homolog of rat Jaggedl expressed by marrow stroma inhibits differentiation of 32D cells through interaction with N otch1. Immunity 1998; 8:43-55.

61. Fehon RG, Kooh PJ, Rebay I, Regan CL, XuT, Muskavitch MA, et al. Molecular interactions between the protein products of the neurogenic 
loci N otch and Delta, two EG F-homologous genes in Drosophila. Cell 1990; 61:523-534.

62. Mukherjee A, Miele L. Chemical and Structural A pproachs to Rational Drug Design. CRC Press 1994: 237-261.

63. H sieh JJ, Henkel T, Salmon P, Robey E, Peterson MG , H ayward SD. Truncated mammalian N otchl activates CBF1/RBPJk-repressed genes by a mechanism resembling that of Epstein-Barr virus EBN A2. Mol C ell Biol 1996; 16:952-959.
64. Boulikas T. Status of gene therapy in 1997: Molecular mechanisms, disease targets, and clinical application. Gene Ther Mol Biol 1998; 1:1-172. 65. Martin F, Boulikas T.The challenge of liposomes in gene therapy. Gene Ther Mol Biol 1998; 1:173-214.

66. Pear W S,Aster JC, Scott ML, Hasserjian RP, Soffer B, Sklar J et al. Exclusive development ofT cell neoplasms in mice transplanted with bone marrow expressing activated N otch alleles.J Exp Med 1996; 183:2283-2291. 